\title{
Renal access in PNL under sonographic guidance: Do we really need to insert an open end ureteral catheter in dilated renal systems? A prospective randomized study
}

\author{
Bilal Eryildirim, Murat Tuncer, Emre Camur, Fatih Ustun, Fatih Tarhan, Kemal Sarica \\ Dr. Lütfi Kirdar Training and Research Hospital Urology Clinic, Istanbul, Turkey.
}

\begin{abstract}
Summary Purpose: To evaluate the true necessity of open end ureteral catheter insertion in patients with moderate to severe pelvicalyceal system dilation treated with percutaneous nephrolithotomy (PNL) under sonographic guidance.

Patients and methods: 50 cases treated with PNL under sonographic guidance in prone position for solitary obstructing renal stones were evaluated. Patients were randomly divided into two groups; Group 1: Patients in whom a open end ureteral catheter was inserted prior to the procedure; Group 2: Patients receiving no catheter before PNL. In addition to the duration of the procedure as a whole and also all relevant stages as well, radiation exposure time, hospitalization period, mean nephrostomy tube duration, mean drop in $\mathrm{Hb}$ levels and all intra and postoperative complications have been evaluated. Results: Mean size of the stones was $308.5 \pm 133.2 \mathrm{~mm}^{2}$. Mean total duration of the PNL procedure in cases with open end ureteral catheter was significantly longer than the other cases $(p<0.001)$. Evaluation of the outcomes of the PNL procedures revealed no statistically significant difference between two groups regarding the stone-free rates ( $86 \%$ vs $84 \%$ ).

Additionally, there was no significant difference with respect to the duration of nephrostomy tube, hospitalization period and secondary procedures needed, complication rates as well as the post-operative $\mathrm{Hb}$ drop levels in both groups $(p=0.6830)$. Conclusions: Our results indicate that the placement of an open end ureteral catheter prior to a PNL procedure performed under sonographic access may not be indicated in selected cases presenting with solitary obstructing renal pelvic and/or calyceal stones.
\end{abstract}

KEY WORDS: Percutaneous nephrolithotomy; Ureteral catheter; Renal stone; Ultrasonographic access.

Submitted 12 July 2017; Accepted 7 August 2017

\section{INTRODUCTION}

Following its first application in 1976, percutaneous nephrolithotomy (PNL) technique has evolved substantially over the last three decades and became the preferred choice in the management of larger stones $(>2 \mathrm{~cm}$ ) both in adults and children (1-3). Although the procedure is safe and successful with stone-free rates of $>90 \%$, certain complications may develop during all stages as well as early and late follow-up period of this procedure (4-9).

Related to this subject, an appropriate initial puncture of the most desirable calyx of the kidney is of paramount importance and access can be established either under flu- oroscopic and/or ultrasonographic guidance. Although fluoroscopic guidance has been used as the most common method for a long period of time, increasing experience in sonographic applications has enabled endourologists to use this method more commonly than ever to get an access to the renal collecting system. Use of sonography will allow the surgeon to identify the pelvicalyceal system as well as the surrounding organs in a safe manner (particularly in relatively dilated systems) to reduce the radiation exposure in a meaningful manner $(10,11)$. On the other hand, an open end ureteral catheter has been commonly used during percutaneous stone removal procedures to visualise the renal collecting system, avoiding the passage of small stone fragments into the ureteric lumen and lastly but most importantly to dilate the renal collecting system to ease the puncture when needed. Despite all these wellestablished advantages however, insertion of an "open end ureteral catheter" may certainly be associated with some possible problems. First of all, a certain injury to the urethra particularly in male cases as well as to the mucosa of the relevant ureter could be caused. Additionally, loss of time due to the insertion of the catheter first in supine position and turning of the case into prone position will further prolong the duration of the procedure (the duration of the anesthesia as well). Thus, in the light of the safe and practical renal puncture in a quick manner in dilated kidneys as well as the problems related to the placement of a catheter use of an open end ureteral catheter in all cases becomes really questionable.

In this present study we aimed to evaluate the true necessity of open end ureteral catheter insertion prior to PNL for a succesful procedure as well as the safety of renal puncture performed under sonographic guidance in patients with pelvicalyceal system dilation (Grade 2 or higher) by comparing two group of cases treated with and without insertion of an open end ureteral catheter before PNL.

\section{Patients and methods}

\section{Study population}

Between January 2015 and January 2017, of all the 236 cases undergoing PNL, procedure in our department, 72 patients meeting the inclusion criteria were included into study program and randomized. Upon randomization 
while 27 cases in Group 1 and 28 cases in Group 2 were operated with PNL technique, cases who were not operated due to some certain reasons were excluded from the study program. Moreover, 2 cases in Group 1 and 3 cases in Group 2 were lost to follow-up for several reasons and finally 50 cases (31 males, 19 females) were analyzed. Patients' enrollment algorithm has been illustrated in Figure 1.

In an attempt to assess the sample size, power analysis was made by using $G^{*}$ Power (v3.1.7) program.

Depending on the index of effect size of Cohen; supposing that the evaluations between two independent groups will have the highest effect size $(d=0.85)$, our calculations did show that at least 23 cases should be included into each group. Additionally, taking the possibility of patient drop-out risk during the study program, final number of the cases in each group has been proposed to be 25 .

While cases presenting with pelvicalyceal system dilation (Grade 2 or higher) due to moderate sized solitary renal pelvic and/or calyceal stones were included into the study program, all other cases with a detectable pathology with respect to the integrity of the ureter prior to the PNL were excluded from the study program.

Patients with renal anomalies, non-dilated renal collecting systems and younger than 18 years of age were also excluded from the study program.

\section{Study design}

This study is a prospective single center, randomized clinical trial with balanced randomization [1:1] which was performed in the referral hospital Dr. Lutfi Kirdar Kartal Training and Research Hospital. For randomization procedure a simple randomization method by generating a random digit (0-60 in each group) has been used. Even numbers have been used for cases in whom an open end ureteral catheter was inserted and odd numbers have been used for cases whom operated without an open end ureteral catheter.

Study protocol was approved by the Ethics Committee of the relevant hospital (September 08, 2016-2016/514/91/3). All steps of the study were planned and applied carefully according to Helsinki Declaration.

All PNL procedures were performed in prone position by experienced urologists and access to the renal collecting system was performed under sonographic guidance. Depending on the placement of an open end ureteral catheter, the patients were divided into two different groups namely; Group 1: Patients in whom a 5 French (F) open end ureteral catheter was inserted prior to the procedure; Group 2: Patients not receiving an open end ureteral catheter insertion before PNL.

Following a complete biochemical and radiological evaluation; patients with urinary tract infections were treated with appropriate culture test based antibiotics.

Regarding the radiological evaluation, ultrasonography (USG), kidney-ureter-bladder (KUB) film and low-dose computed tomography (CT) have been performed to assess the renal anatomy, degree of hydronephrosis, position of the relevant kidney with neighboring organs and location, burden of the stone(s) to be treated. Stone area has been calculated by using the two dimensions of the stone(s) from CT images.

While the primary outcome of our study was to evaluate and compare the ultimate stone free rates after both approaches, secondary end points were the evaluation of operational duration, complication rates, mean fluoroscopy time and hospital stay period in both groups in a comparative manner.

Figure 1. CONSORT Flow Diagram of study. 


\section{Surgical technique of PNL procedure}

Following general anesthesia, while performing cystoscopy, a $5 \mathrm{~F}$ open end ureteral catheter was placed into the relevant ureter till ureteropelvic junction area in Group 1 cases in the lithotomy position, no open end ureteral catheter was inserted in Group 2 cases and a prone position has been given directly in these cases.

An appropriate calyceal puncture under full sonographic guidance was done with a 18 gauge percutaneous entrance needle (Boston Scientific, Natick, MA, USA).

Following puncture of the kidney, a 0.038 inch guide wire was inserted into the collecting system (into the ureter when possible) and Amplatz mechanical dilatators were used for percutaneous tract dilatation (Amplatz sheath, Boston Scientific, Natick, MA, USA) until 28-30 F. Following the placement of an appropriate access sheath a standard 26 F nephroscope (Karl Storz, Tuttlingen, Germany) was placed directly into the kidney through the tract and the stone disintegrated using an ultrasonic lithotripsy probe (Swiss Lithoclast $^{\circledR}$, EMS Electro Medical System, Nyon, Switzerland). Fragments were removed by suction, tipless basket, or grasping forceps. At the end of the procedures, a re-entry nephrostomy catheter (14 F) was placed, and an antegrade pyelography was performed to check for possible complications in all cases. The open end ureteral catheter was removed at the end of the operation in Group 1 cases. The nephrostomy tube was removed postoperatively on the first or second day as soon as the urine became clear.

\section{Outcome assessment}

All patients were re-evaluated by a plain abdominal film and/or sonography after 24 hours and by a non-contrast abdominal tomography at the end of a 4 weeks period. The operation was considered successful if there were no fragments at all or if the size of the residual fragments were smaller than $4 \mathrm{~mm}$.

In addition to the duration of the procedure as a whole and also all relevant stages as well, the duration of radiation exposure, hospitalization period along with the mean duration of nephrostomy tube, mean drop in hemoglobin $(\mathrm{Hb})$ levels, all intraoperative, and postoperative complications have been evaluated and recorded.

\section{Results}

A total of 50 cases (31 males/19 females M/F: 1.63) were treated with standard PNL for moderate sized solitary calyceal or pelvic stones and sonographic guidance was used for renal puncture. While the age of the cases ranged from 22-72 years (mean 44.90 +/- 12.32 years, 95\% CI: 41.00-48.40), the mean size of the treated stones was $308.5+/-133.2 \mathrm{~mm}^{2}$, (95\% CI: 270.7-346.4). Demographic as well as radiologic characteristics of the cases are given in Table 1 . The stones were located in the calyceal system in 28 cases ( 6 cases upper, 9 cases middle, 13 cases lower calyx) and in the renal pelvis in 22 cases. There was no significant difference regarding the size of the stones in both groups.

Evaluation of our findings in both groups revealed following data.

Regarding the duration of the treatment as a whole or in certain parts of the procedure, our results show clearly that the mean total duration of the PNL procedure in cases with open end ureteral catheter was significantly longer than the other cases $(85.80+/-16.18$ vs $60.84+/-13.21$ minute respectively, $\mathrm{p}<0.001$ ). The mean duration for an open end ureteral catheter insertion in Group 1 was 27.96 +/- 5.86, (95\% CI: 25.54-30.38) min. and this time period was the main cause for prolonged total operative time in these cases. On the other hand however, there was no statistically significant difference with respect to the mean duration of other isolated stages of PNL procedure (renal puncture, access sheath placement, stone disintegration and removal) as shown in Table 2.

As an important parameter again, although the mean fluoroscopic exposure time was relatively longer in cases treated with an open end ureteral catheter, this difference was not statistically significant $(\mathrm{p}=0.3595)$. Evaluation of the outcomes of the PNL procedures in terms of success rates as well as early post-operative follow-up data revealed no statistically significant difference between the two groups regarding the stone-free rates ( $84 \%$ vs $88 \%$ ) and also the percentage of the cases with residual fragments sizing $>4$ $\mathrm{mm}(\mathrm{p}=1.00)$ (Table 3). Additionally, when we evaluated the cases with respect to the duration of nephrostomy tube, hospitalization period and secondary procedures needed Double J stent placement and ureteroscopy (URS) again we were not able to show any significant difference in these

\section{Statistical analysis}

The Prism 5.0 (GraphPad Software, San Diego, CA) was used for the statistical analysis. Data are presented as mean standard deviation of mean. Mann Whitney $U$ test was used for both comparison of descriptive statistical methods and evaluation of quantitative data and Fisher exact test were used to compare the qualitative data between two groups, a twosided $\mathrm{p}<0.05$ was considered statistically significant.
Table 1.

Evaluation of patient and stone characteristics in both groups.

\begin{tabular}{|c|c|c|c|c|}
\hline Variables $^{\mathrm{a}}$ & $\begin{array}{l}\text { Overall } \\
n=50\end{array}$ & $\begin{array}{c}\text { Group } 1 \\
\text { Ureteral catheter (+) } \\
n=25\end{array}$ & $\begin{array}{c}\text { Group } 2 \\
\text { Ureteral catheter (-) } \\
n=25\end{array}$ & $P$ value \\
\hline $\begin{array}{l}\text { Age, year; mean } \pm \text { SD } \\
\text { (range) }\end{array}$ & $\begin{array}{c}44.9012 .32 \\
(22-72)\end{array}$ & $\begin{array}{c}47.0011 .05 \\
(26-60)\end{array}$ & $\begin{array}{c}42.8013 .36 \\
(22-72)\end{array}$ & 0.2175 \\
\hline $\begin{array}{l}\mathrm{BMI}, \mathrm{kg} / \mathrm{m}^{2} ; \text { mean } \pm \mathrm{SD} \\
\text { (range) }\end{array}$ & $\begin{array}{l}27.184 .14 \\
(18.2-38.0)\end{array}$ & $\begin{array}{r}28.524 .20 \\
(22.3-38.0)\end{array}$ & $\begin{array}{l}25.843 .69 \\
(18.2-34.5)\end{array}$ & 0.0380 \\
\hline $\begin{array}{l}\text { Stone burden, } \mathrm{mm}^{2} \text {; mean } \pm \mathrm{SD} \\
\text { (range) }\end{array}$ & $\begin{array}{c}308.5133 .2 \\
(195-570)\end{array}$ & $\begin{array}{c}297.8106 .5 \\
(195-570)\end{array}$ & $\begin{array}{c}319.2157 .0 \\
(200-530)\end{array}$ & 0.7784 \\
\hline $\begin{array}{l}\text { HU, Hounsfield unit; mean } \pm \text { SD } \\
\text { (range) }\end{array}$ & $\begin{array}{l}812198.3 \\
(450-1500) \\
\end{array}$ & $\begin{array}{c}766.3164 .5 \\
(450-1480)\end{array}$ & $\begin{array}{c}857.5202 .4 \\
(470-1500)\end{array}$ & 0.1276 \\
\hline $\begin{array}{l}\text { Degree of hydronephrosis, Grade; mean } \pm \text { SD } \\
\text { (range) }\end{array}$ & $\begin{array}{l}2.220 .50 \\
(2-4)\end{array}$ & $\begin{array}{c}2.160 .47 \\
(2-4)\end{array}$ & $\begin{array}{l}2.280 .54 \\
(2-4)\end{array}$ & 0.3024 \\
\hline
\end{tabular}


Table 2.

Evaluation of the procedure related parameters with an emphasis on the duration of the interventional steps in both groups.

\begin{tabular}{|c|c|c|c|c|}
\hline Variables $^{a}$ & $\begin{array}{l}\text { Overall } \\
n=50\end{array}$ & $\begin{array}{c}\text { Group } 1 \\
\text { Ureteral catheter (+) } \\
\qquad n=25\end{array}$ & $\begin{array}{c}\text { Group } 2 \\
\text { Ureteral catheter (-) } \\
\qquad n=25\end{array}$ & $P$ value \\
\hline Mean duration of the procedure (min) & 73.1218 .90 & 85.8016 .18 & 60.8413 .21 & $<0.0001$ \\
\hline $\begin{array}{l}\text { Mean duration of open end catheter } \\
\text { insertion (min) }\end{array}$ & - & 27.965 .86 & - & - \\
\hline $\begin{array}{l}\text { Mean duration of access to the collecting } \\
\text { system (min) }\end{array}$ & 5.422 .32 & $5.28 \quad 2.08$ & 5.762 .45 & 0.4909 \\
\hline $\begin{array}{l}\text { Mean duration of dilation and access sheath } \\
\text { placement (min) }\end{array}$ & 10.343 .96 & 10.083 .22 & 10.674 .02 & 0.5118 \\
\hline $\begin{array}{l}\text { Mean duration of fragmentation and stone } \\
\text { removal (min) }\end{array}$ & 27.3812 .53 & 25.9611 .80 & 28.8012 .86 & 0.3896 \\
\hline Mean fluoroscopy time (sec.) & 18.209 .60 & 19.6011 .08 & 17.367 .63 & 0.3595 \\
\hline
\end{tabular}

the ureteric lumen could be a significant drawback of this approach however, as we tend to remove all relatively larger fragments during the procedure with great care, there will be very limited chance for fragment relocation in these cases with moderate sized calculi. Moreover, it is clear that passage of the fragments down into the ureteric lumen might occur despite given care and open end ureteral catheter insertion (like the case in Group 1 of our study) in a certain percentage of the cases. values. Last but not least as another important parameter to be evaluated, there was also no notable difference regarding the post-operative drop in $\mathrm{Hb}$ levels in both groups ( $\mathrm{p}=$ 0.6830).

Finally, evaluation of the complications in the light of modified Clavien grading system demonstrated no statistically significant difference between the two groups particularly concerning bleeding after PNL (Table 4). As summarized in this table, while one case in each group required double $\mathrm{J}$ stent insertion due to the prolonged urine leakage after nephrostomy tube removal, a stone passing into the ureter despite open end ureteral catheter placement was removed with URS in one case of Group 1. Relocation of the disintegrated stone fragments down into

\section{Table 3.}

Evaluation of the outcomes of the procedures in terms of success rates as well as early post-operative follow-up data.

\begin{tabular}{|c|c|c|c|c|}
\hline Variables $^{a, b}$ & $\begin{array}{l}\text { Overall } \\
n=50\end{array}$ & $\begin{array}{l}\text { Group } 1 \\
\text { Ureteral catheter (+) } \\
\qquad n=25\end{array}$ & $\begin{array}{c}\text { Group } 2 \\
\text { Ureteral catheter (-) } \\
\qquad n=25\end{array}$ & $P$ value \\
\hline b Stone free rate; $n,(\%)$ & $43(86.0)$ & $21(84.0)$ & $22(88.0)$ & 1.0000 \\
\hline${ }^{\mathrm{b}}$ Residual stone $>4 \mathrm{~mm} \mathrm{n},(\%)$ & $7(14.0)$ & $4(16.0)$ & $3(12.0)$ & 1.0000 \\
\hline${ }^{a}$ Mean drop in hb levels (g/dL) & 1.520 .68 & 1.600 .69 & 1.450 .57 & 0.6830 \\
\hline a Mean duration of nephrostomy (day) & 1.860 .88 & 1.830 .79 & 1.920 .92 & 0.7246 \\
\hline a Mean hospital stay (day) & 2.880 .96 & 2.840 .96 & 2.921 .03 & 0.9010 \\
\hline b Secondary intervention; n, (\%) & $3(6.0)$ & $2(8.0)$ & $1(4.0)$ & 1.0000 \\
\hline
\end{tabular}

\section{Table 4.}

Evaluation of the type and grade of complications according to modified Clavien classification in both groups.

\begin{tabular}{|c|c|c|c|c|c|}
\hline Grade & Complication & $\begin{array}{l}\text { Overall } \\
n=50\end{array}$ & $\begin{array}{c}\text { Group } 1 \\
\text { Ureteral } \\
\text { catheter (+) } \\
n=25\end{array}$ & $\begin{array}{c}\text { Group } 2 \\
\text { Ureteral } \\
\text { catheter (-) } \\
n=25\end{array}$ & ${ }^{\mathrm{b}} \mathbf{P}$ value \\
\hline 1 & $\begin{array}{l}\text { Fever > } 38 \text { OC; } n,(\%) \\
\text { Hemorrhage not requiring blood transfusion; } n,(\%)\end{array}$ & $\begin{array}{l}5(10.0) \\
4(8.0)\end{array}$ & $\begin{array}{c}3(12.0) \\
2(8.0)\end{array}$ & $\begin{array}{l}2(8.0) \\
2(8.0)\end{array}$ & 1.0000 \\
\hline 2 & Hemorrhage requiring blood transfusion; $n,(\%)$ & $2(4.0)$ & $1(4.0)$ & $1(4.0)$ & 1.0000 \\
\hline 3a & Double J stent placement for urine leakage > 24 h; n, (\%) & $2(4.0)$ & $1(4.0)$ & $1(4.0)$ & 1.0000 \\
\hline$\overline{3 b}$ & Endoscopic treatment for ureteral stone; $n,(\%)$ & $1(2.0)$ & $1(4.0)$ & - & 1.0000 \\
\hline
\end{tabular}

\section{Discussion}

Percutaneous nephrolithotomy has been performed as a minimally invasive method of removing kidney stones since 1976. As a result of the improvements in operative technique and miniaturization of the available equipment, this approach is now commonly performed as a safe and successful management option in larger stones. However, despite the high stone free rates obtained in a single session; PNL could be associated with certain types of complications like bleeding, organ perforation and sepsis (12). Such complications could be encountered during all steps of PNL among which the access to the renal collecting system seems to be the most important one (13).

Related to this subject, an appropriate initial puncture of the most desirable calyx of the kidney is extremely important for a successful and safe procedure by limiting the chance of both bleeding as well as injury to the surrounding organs (e.g. colon, spleen, liver, pleura, lung). Access to the renal collecting system from the most suitable calyx can be established either under fluoroscopic and/or sonographic guidance. Main aim of these two different guiding procedures should be a direct path which will be identified and used from the skin through the papilla of the desired calyx (14). Accumulated experience so far has clearly demonstrated that each of these methods could be associated with certain advantages as well as disadvantages. Related to this subject, during fluoroscopic guidance renal puncture is usually done after the placement of an open end ureteral catheter through cystoscopy. Use of this catheter will in turn allow the 
surgeon to dilate the collecting system with saline injection for an easy puncture particularly in cases with minimal or no dilation and also to visualize the pelvicalyceal system with contrast medium. To accomplish this task however, patients are initially placed into a lithotomy position for the placement of the ureteral catheter and then brought into the prone position to perform the kidney puncture and access to the renal collecting system. It is clear that these procedures and maneuvers will certainly lengthen the total operational time for these cases being operated under general anesthesia. Additionally and more importantly a certain injury to the urethra particularly in male cases as well as to the mucosa of the relevant ureter could be caused. On the other hand again, the administration of contrast agent may cause severe, contrast-related complications and the contrast agent may affect the opacity of the stone, causing challenges for the endourologist during stone manipulation. Moreover, the fear of injuring structures during a 'blind' approach under fluoroscopic guidance up to the renal capsule constitutes another major concern. Last but not least, using fluoroscopy during percutaneous access to the kidney is accompanied by the exposure of the operators, patients as well as the other working staff to radiation. Long-term ionizing radiation may lead to considerable hazardous effects on certain organs (15). Taking the above mentioned problems related to fluoroscopic access into account, endourologists began to use sonographic guidance more commonly then ever in an attempt to avoid such certain problems with some certain advantages. First of all, this approach is totally free of ionizing radiation with shorter operating duration (16). Additionally, this form of guidance allows the endourologist to identify the neighboring organs in an accurate manner to minimize the risk of injury (17). Lastly, the European Association of Urology recommends the initial puncture under sonographic guidance because it reduces radiation hazards (18).

As stated above use of sonographic guidance in gaining access to the renal collecting system gained more importance than ever in the last decade. Related with this issue, in a prospective and randomized study $\mathrm{Zu} \mathrm{W}$ et al., aimed to compare the safety and efficacy of fluoroscopic (FG), total ultrasonographic (USG) and combined (CG) guidance for percutaneous renal access during mini-percutaneous nephrolithotomy (mini-PCNL) in a total of 450 consecutive patients with renal stones larger than $2 \mathrm{~cm}$. While the overall complication rates using the Clavien grading system as well as stone free rates were similar between the three groups; multiple-tracts PNL were used more frequently in the FG and CG group than USG group and the mean access time was longer in CG than for FG and USG group patients. Mean total radiation exposure time however was significantly greater for FG than for CG (19). In another study again, 45 children with unilateral stones underwent PNL procedures under totally sonographic guidance with a mean time to establish access as 2.9 (range 2.1-5) min. Blood loss requiring transfusion, sepsis, adjacent organ injury and kidney loss were not observed in any case and the authors concluded that the ultrasound-guided mini-PCNL is feasible and safe in patients aged $<3$ years, without major complications or radiation exposure (20). Last but not least, in their well organized systematic literature review including 18 studies with 2919 patients, Liu Q et al. stated in the final analysis that when compared with fluoroscopic guidance, use of ultrasonography provided shorter puncture time, higher success rate of fist puncture, less blood loss, and less complications as the main advantages of this approach (21).

On the other hand again, sonographic access to the kidney will be more practical and safe in relatively dilated renoureteral units in experienced hands. Easy and quick identification of the renal structures but most important the desired calyx in such dilated kidneys will allow the endourologist to establish the puncture in a safe manner which will diminish the importance of open end ureteral catheter insertion to a certain extent. Thus, taking the advantages of renal puncture in a safe and quick manner under sonographic guidance in dilated kidneys as well as the problems related to open end ureteral catheter placement into account use of an open end ureteral catheter in all cases becomes really questionable. Regarding the performance of percutaneous nephrolithotomy without open end ureteral catheter insertion, there is highly limited data reported so far in the literature. Only one study conducted by Tabibi et al. compared the outcomes of renal calyceal system puncture with and without retrograde pyelography in 55 patients with opaque renal calculi. They were able to show no differences in outcome, infection, operative time, duration of hospital stay, and radiation exposure, indicating that ureteral catheter placement may be precluded (22). We believe that our current study is a comprehensive one focusing on this critical issue in a detailed manner.

In this present study we aimed to evaluate the true necessity of open end ureteral catheter insertion in terms of the success as well as safety of renal puncture in patients with diated pelvicalyceal system (Grade 2 or higher) performed under sonographic guidance by comparing them with the cases in whom the catheter was inserted. Our results demonstrate clearly that the mean total duration of the PNL procedure in cases with open end ureteral catheter was significantly longer than the other cases. However, use of open end ureteral catheter did not shorten the renal access time in both groups of cases indicating that the presence of a dilated system doesn't require a catheter placement particularly in the light of the disadvantages mentioned above.

Evaluation of the outcomes of the PNL procedures in terms of success rates as well as early post-operative follow-up data revealed no statistically significant difference between the two groups regarding the stone-free rates ( $84 \%$ vs $88 \%$ ). Additionally, when we evaluated our cases in both groups with respect to nephrostomy tube duration, hospitalization period and percentage of secondary procedures, no statistically significant difference again could be demonstrated from these aspects. Last but not least, as an important parameter again, although the mean fluoroscopic exposure time was relatively longer in cases treated with open end ureteral catheter, this difference was not statistically significant. Our results demonstrate clearly that despite its wellknown advantages during PNL procedure performed under fluoroscopic guidance; placement of an open end ureteral catheter may not really be necessary particularly in selected cases with a dilated renal collecting system 
operated under sonographic guidance. Renal puncture under sonographic guidance can be done in a safe and practical manner in experienced hands in such cases without any need for such a catheter placement. Furthermore visualisation of the entire collecting system could be done via antegrade way in all these cases whenever needed. It should be kept in mind that; open end ureteral catheter insertion is a time consuming procedure which will in turn definitely prolong the total duration of a certain procedure during which the patient receives anesthesia in an unusual position. Additionally, when we add the time period needed for the change of the position from lithotomy to prone in the majority of the cases again the total duration of the intervention (as well as the anesthesia) will further increase in these cases. Additionally, it is very clear that urethra as well as ureter are both exposed to a certain degree of trauma during stent placement particularly in male cases. Taking all these facts into account, we believe that an open end ureteral catheter may not be inserted in selected cases treated with PNL under sonographic access for solitary renal pelvic and/or calyceal stones causing dilatation in the upper urinary tract.

Our study may have one limitation: The number of cases included and evaluated may be small. But taking the lack of publications regarding this issue and comprehensive evaluation of the necessity for an open end ureteral catheter performing PNL in dilated renal systems under sonographic guidance, we believe that our current findings will certainly be contributive enough to the existing literature on this critical subject.

\section{Conclusions}

In the light of the findings obtained in our current study and the above mentioned well known associated problems, we believe that placement of an open end ureteral catheter prior to a PNL procedure performed under sonographic access may not be indicated in selected cases presenting with solitary renal pelvic and/or calyceal stones causing dilatation in the upper urinary tract.

\section{References}

1. Fernstrom I, Johansson B. Percutaneous pyelolithotomy. A new extraction technique. Scand J Urol Nephrol. 1976; 10:257-9.

2. Tanriverdi $O$, Boylu $U$, Kendirci $M$, et al. The learning curve in the training of percutaneous nephrolithotomy. Eur Urol. 2007; 52:206-11.

3. Tiselius HG, Ackermann D, Alken P, et al. Working Party on Lithiasis, European Association of Urology. Guidelines on urolithiasis. Eur Urol. 2001; 40:362-71.

4. Kim SC, Kuo RL, Lingeman JE. Percutaneous nephrolithotomy: an update. Curr Opin Urol. 2003; 13:235-41.

5. Basiri A, Tabibi A, Nouralizadeh A, et al. Comparison of safety and efficacy of laparoscopic pyelolithotomy versus percutaneous nephrolithotomy in patients with renal pelvic stones: a randomized clinical trial. Urol J. 2014; 1:1932-7.

6. de la Rosette J, Assimos D, Desai M, et al. The Clinical Research Office of the Endourological Society Percutaneous Nephrolithotomy Global Study: indications, complications, and outcomes in 5803 patients. J Endourol. 2011; 25:11-7.
7. Michel MS, Trojan L, Rassweiler JJ. Complications in Percutaneous Nephrolithotomy. Eur Urol. 2007; 51:899-906.

8. Tefekli A, Ali Karadag M, Tepeler K, et al. Classification of percutaneous nephrolithotomy complications using the modified clavien grading system: looking for a standard. Eur Urol. 2008; 53:184-90.

9. Mousavi-Bahar SH, Mehrabi S, Moslemi MK. Percutaneous nephrolithotomy complications in 671 consecutive patients: a singlecenter experience. Urol J. 2011; 8:271-6.

10. Desai M, Ridhorkar V, Patel S, et al. Pediatric percutaneous nephrolithotomy: asssessing impact of technical innovations on safety and efficacy. J Endourol. 1999; 13:359-64.

11. Zegel HG, Pollack HM, Banner MC, et al. Percutaneous nephrostomy. comparison of sonographic and fluoroscopic guidance. Am J Roentgenol. 1981; 137:925-7.

12. el-Nahas AR, Eraky I, Shokeir AA, et al. Factors affecting stonefree rate and complications of percutaneous nephrolithotomy for treatment of staghorn stone. Urology. 2012; 7:1236-41.

13. Aslam MZ, Thwaini A, Duggan B, et al. Urologists versus radiologists made PCNL tracts: the UK experience. Urol Res 2011; 39:217-21.

14. Agarwal M, Agrawal MS, Jaiswal A, et al. Safety and efficacy of ultrasonography as an adjunct to fluoroscopy for renal access in percutaneous nephrolithotomy. BJU Int. 2011; 108:1349.

15. Hellawell GO, Mutch SJ, Thevendran G, et al. Radiation exposure and the urologist: what are the risks? J Urol. 2005; 174:948-52.

16. Basiri A, Ziaee SA, Nasseh $H$, et al. Totally ultrasonography guided percutaneous nephrolithotomy in the flank position. J Endourol. 2008; 22:1453-7.

17. Basiri A, Ziaee A, Kianian H, et al. Ultrasonographic versus Fluoroscopic Access for Percutaneous Nephrolithotomy: a Randomized Clinical Trial. J Endourol. 2008; 22:281-4.

18. European Association of Urology. Guidelines on urolithiasis. 2012 http://www.uroweb.org/gls/pdf/21_Urolithiasis_LR.pdf

19. Zhu W, Jiasheng L, Jian Y, et al. A prospective and randomized trial comparing fluoroscopic, total ultrasonographic, and combined guidance for renal access in mini-percutaneous nephrolithotomy. BJU Int. 2017; 119:612-8.

20. Xiao B, Hu W, Zhang X, et al. Ultrasound-guided mini-percutaneous nephrolithotomy in patients aged less than 3 years: the largest reported single-center experience in China. Urolithiasis. 2016; 44:179-83.

21. Liu Q, Zhou L, Cai X, et al. Fluoroscopy versus ultrasound for image guidance during percutaneous nephrolithotomy: a systematic review and meta-analysis. Urolithiasis. 2016 Nov 22. [Epub ahead of print].

22. Tabibi A, Akhavizadegan $H$, Nouri-Mahdavi $K$, et al. Percutaneous nephrolithotomy with and without retrograde pyelography: A randomized clinical trial. Int Braz J Urol. 2007; 33:19-22.

\section{Correspondence}

Bilal Eryildirim, MD (Corresponding Author)

bilaleryildirim@yahoo.com

Murat Tuncer, MD - murattuncer77@hotmail.com

Emre Camur, MD - emre.camur@outlook.com

Fatih Ustun, MD - drfatihustun@gmail.com

Fatih Tarhan, MD - tarhanf@yahoo.com

Kemal Sarica, MD - saricakemal@gmail.com

Dr. Lütfi Kirdar Training and Research Hospital Urology Clinic Istanbul, Turkey 